\title{
Population specific reference ranges of CD3, CD4 and CD8 lymphocyte subsets among healthy Kenyans
}

\author{
Erick M Bosire ${ }^{1 *}$, Anthony K Nyamache ${ }^{2}$, Michael M Gicheru', Samoel A Khamadi ${ }^{3}$, Raphael W Lihana ${ }^{3}$ \\ and Vincent Okoth ${ }^{3}$
}

\begin{abstract}
Background: The enumeration of absolute CD4 counts is of primary importance for many medical conditions especially HIV infection where therapeutic initiation depends on the count. These ranges tend to vary across populations. However, these ranges have not been comprehensively established in the Kenyan population. Therefore, this study aimed at establishing the reference ranges for the CD4 and CD8 T-lymphocytes in normal healthy individuals in Kenya.
\end{abstract}

Methods: A total of 315 individuals of the ages between 16 and 60 years old, in 5 different regions of the country, were recruited into the study. They were screened for diseases that potentially cause lymphocyte homeostasis perturbation. CD4/CD8 Counts were performed by use of a FACSCalibur flow cytometer (Becton-Dickinson, NJ) equipped with automated acquisition and analysis software. Results were analysed according to age, sex and region.

Results: Results were presented as means and ranges (in parenthesis) generated non parametrically as 2.5 and 97.5

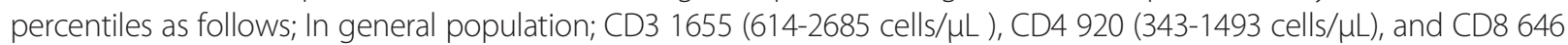

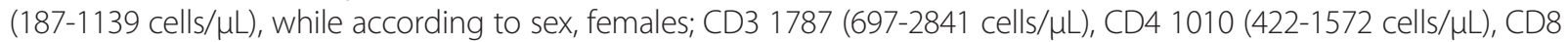

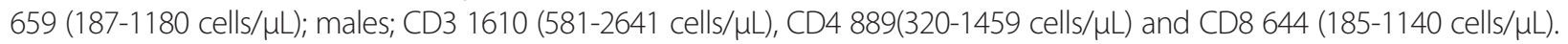
The general reference ranges for CD4/CD8 ratios were as follows; general population 1.57(0.50-2.74), males 1.51(0.49-2.64) and females 1.69(0.55-2.95).

Conclusion: The lymphocyte reference ranges for the Kenyan population are fairly comparable to those established in other African populations. The ranges also differ appreciably from those established in Germany, Italy and Switzerland. Furthermore, the study reported significant differences in the ranges of different population clusters within Kenya, as well us between males and females.

Keywords: CD4/CD8 count, Lymphocyte subsets, HIV-1, Flow cytometry, Reference ranges

\section{Introduction}

Lymphocytes co-ordinate the immune system's response and play a central role in cell mediated immunity [1]. Lymphocyte subset may include; Helper T cells (CD4 T-cells), Cytotoxic T cells (CTLs or CD8 T-cells), Memory $\mathrm{T}$ cells and Regulatory $\mathrm{T}$ cells (Treg cells). Upon encounter with antigens, CD4 T cells become activated and proliferate rapidly secreting cytokines that sends signals and maintain

\footnotetext{
* Correspondence: bosireerick@yahoo.com

'Department of Zoological Science, Kenyatta University, P.O. Box 43844-0100, Nairobi, Kenya

Full list of author information is available at the end of the article
}

active immune response. On the other hand, the CD8 T-cells destroy virally infected cells and tumor cells, and remain inactivated when there is no foreign antigen. In human immunodeficiency virus-1 (HIV-1) infected individuals, lymphocytes (specifically CD4 T-cells) are the viral prime targets. Therefore in these individuals, a CD4 count provides a picture of immune system competence, with higher CD4 counts typically signifying healthier immune systems $[1,2]$. In such application, flow cytometry is used to provide absolute counts, percentages and or ratios of these lymphocyte subsets. Besides HIV management, flow cytometric analysis of peripheral blood lymphocyte

\section{Biomed Central}

(c) 2013 Bosire et al.; licensee BioMed Central Ltd. This is an open access article distributed under the terms of the Creative Commons Attribution License (http://creativecommons.org/licenses/by/2.0), which permits unrestricted use, distribution, and reproduction in any medium, provided the original work is properly cited. 
phenotypes has proven a useful aid in managing a wide range of medical conditions, including autoimmunity, immunodeficiency, infection, malignancy and transplantation [3-5]. Essential to the effective application of this approach is availability of accurate reference values against which results can be meaningfully compared.

Reference ranges that are currently used in Kenya are derived from data obtained from Caucasians who are not African Kenyans. In addition, these ranges do not include age and sex which are very important factors that influence lymphocyte counts [6]. Furthermore, several factors have been associated with these differences in lymphocyte counts. These may include; demographic and genetic factors, current exposure to infectious diseases and behavioral factors on CD3, CD4 and CD8 in HIV-negative populations $[1,2,6]$. Averagely, healthy African and Asian populations have been shown to have lower CD4 lymphocyte counts than their western European and Caucasian counterparts $[2,7,8]$. In addition, women tend to have higher CD4 levels than men with comparable demographic and behavioral patterns $[8,9]$. However, there is still limited data from specific countries to confirm these differences.

The pattern of lymphocyte generation has been shown to affect the levels of circulating lymphocytes in males, females and individuals of different ages. The pattern of $\mathrm{T}$ lymphocyte generation in aging has been associated with dynamic changes in thymic and extrathymic functions along with sequential developmental steps from cells to mature cells [10]. Increased absolute numbers of peripheral blood CD4 cells in females compared to males have been reported [11]. This is perhaps due to androgens which accelerate thymocytes apoptosis and subsequently influence $\mathrm{T}$ cell repertoire with males tending to have less CD4 cells than females [12,13]. Sex and age related variations in the lymphocyte subsets contribute to age and sex related diseases including autoimmune disorders in females and leukemia or lymphoma in males and elderly patients $[14,15]$. Other factors which have received little attention but also affect the normal lymphocyte levels include; dietary patterns, body mass index and smoking habits [16-18]. The influence of these many factors point out to the fact that the reference ranges of one population might not be accurately used as a reference range for another. This might give an inaccurate interpretation of the immune status of the individuals.

Several efforts to establish reference ranges have indicated differences in lymphocyte levels between African and Western populations $[2,3,9,19]$. In one community in Kenya, general clinical ranges have been shown to significantly differ from the ranges from other parts of the continent [20]. These ranges are also appreciably different from those reported in a neighboring country [21]. The two studies in Kenya had indicated a possibility of having remarkably different ranges of lymphocyte subsets within the Kenyan population [20,22]. This necessitates the need for a comprehensive reference range establishment using subjects from different regions of the country. In this study we report comprehensive reference ranges for $\mathrm{CD} 3, \mathrm{CD} 4$ and CD8 cutting across representative regions of the country. The study provides ranges specific for males, females and for different ages.

\section{Materials and methods}

\section{Study subjects and samples}

A total of 315 adults (222 men and 85 female) were recruited into the study after giving consent. This study was ethically approved by Kenya National ethical Review committee before execution. The individuals who were included in the study were healthy adults between 16 and 55 (categorized as 16-19, 21-30 and 31-55) years of age presenting for routine blood donation at the regional centers. These regional blood transfusion centers included; Mombasa, Nakuru, Kisumu, Embu, and Nairobi. A structured questionnaire was used to collect information on the history and general health status of the donors (See Additional file 1). Donors who confirmed to have a history of conditions that cause immune perturbations were excluded from the study. Further, the samples were screened for HIV, Hepatitis B virus (HBV), Hepatitis C virus $(\mathrm{HCV})$, malaria, and syphilis after blood collection, and samples that tested positive were excluded from the study. Blood samples were collected by venipuncture into EDTA vacutainer tubes and analyzed immediately after collection.

\section{Screening for malaria, syphilis, HIV, HCV and HBV}

Enzyme linked immunoassays were used in screening for these conditions. Commercially available kits containing purified antigens were used. The kits included: ICE* Syphilis, Murex anti-HCV (version 4.0), Hepanostika HBsAg Ultra kit, Murex HIV-1.2.0 (Abbot) and malaria antigen detection kit (Creative diagnostics).

\section{Sample collection and analysis}

The lymphocyte subsets were analyzed on a FACSCalibur flow cytometer (Becton Dickinson Immunocytometry Systems, San Jose, California) with three monoclonal antibodies (BD Tritest CD4-FITC/CD8-PE/CD3-PerCP reagent) according to the manufacturer's instructions. The FACSCaliber was calibrated and reconfirmed daily using the BD Calibrite beads and BD-FACSComp software, version 2.0 for setting the photomultiplier tube voltages, setting the fluorescence compensation and checking instrument sensitivity before use. A control sample of commercially available whole blood was run daily to optimize the instrument settings. The CD45 versus the side scatter (SSC) dot plot was visually inspected 
Table 1 The means and medians of the lymphocyte subsets in the study population

\begin{tabular}{|c|c|c|c|c|c|c|c|}
\hline \multicolumn{8}{|c|}{ T lymphocyte subset } \\
\hline & \multicolumn{2}{|l|}{ CD3 } & \multicolumn{2}{|l|}{ CD4 } & \multicolumn{2}{|l|}{ CD8 } & \multirow{2}{*}{$\begin{array}{l}\text { Ratios } \\
\text { CD4/CD }\end{array}$} \\
\hline & Absolute count ${ }^{*}$ & $\%^{x}$ & Absolute count ${ }^{*}$ & $\%^{x}$ & Absolute count ${ }^{*}$ & $\%^{x}$ & \\
\hline Mean & 1655 & 67 & 920 & 37 & 646 & 26 & 1.57 \\
\hline Median & 1580 & 67 & 884 & 37 & 559 & 25 & 1.47 \\
\hline Ranges & $614-2685$ & $50-78$ & $343-1493$ & $24-48$ & $187-1139$ & $13-36$ & $0.50-2.74$ \\
\hline
\end{tabular}

${ }^{*}$ Expressed as cells $/ \mu \mathrm{L}$ of blood.

${ }^{\times}$Expressed as a percentage of total lymphocytes.

to make sure they appear as a bright compact cluster, with low SSC. Analysis did not proceed if populations were diffuse and if there was little or no separation between clusters [15].

\section{Data analysis}

Non parametric reference range determination was employed by estimating the 2.5 and 97.5 percentile [23]. The significance of differences between the mean absolute counts and percentages of the Lymphocyte subsets were estimated using the Analysis of Variance (ANOVA) and T-test. Multiple comparisons were done using Tukey's test. Correlation analysis was applied in determining the relationship between lymphocyte subset levels and age.

\section{Results}

Among the 315 individuals between the ages 16-60 years, $61.7 \%$ (222) were men and $38.4 \%$ (85) were female. Their blood samples were analyzed for CD3, CD4 and CD8 lymphocyte subset for establishment of reference ranges.
These reference ranges were also compared across the sampled geographical regions, by age as well as sex.

\section{General distribution of the T-lymphocytes for the study population}

The CD3, CD4 and CD8 counts and ranges for the general study population were determined. The means, median, percentages and ranges of these lymphocytes, as well as the CD4/CD8 ratios were determined (Table 1).

\section{Lymphocyte subsets in the different Kenyan regions}

Mean absolute counts of the different regions were compared using ANOVA. Significantly different means were further subjected to Tukey's test to show differences between each of the regions. The difference in the mean CD3 of Nairobi and Rift valley regions was minimal compared to the difference in the CD3 mean of the Lake Victoria basin region. The Lake Victoria region had the lowest CD3 mean compared to all other regions. These differences in the $\mathrm{CD} 3$ absolute count means were

Table 2 Means, medians and ranges of the lymphocyte subsets for the different geographical regions in Kenya

\begin{tabular}{|c|c|c|c|c|c|c|c|}
\hline \multirow[t]{2}{*}{ Region } & \multicolumn{7}{|c|}{ Lymphocyte subset } \\
\hline & & CD3 count & CD3\% & CD4 count & CD4\% & CD8 count & $\mathrm{CD} 8 \%$ \\
\hline \multirow[t]{3}{*}{ Nairobi } & Mean \pm SD & $1841 \pm 486 c$ & $69 \pm 6 a$ & $1046 \pm 283 c$ & $39 \pm 6 a$ & $717 \pm 260 c$ & $26 \pm 5 c$ \\
\hline & Median & 1824 & 69 & 1007 & 39 & 691 & 26 \\
\hline & Range & $908-2661$ & $55-79$ & 517-1506 & $27-48$ & $266-1165$ & $16-35$ \\
\hline \multirow[t]{3}{*}{ Eastern } & Mean \pm SD & $1728 \pm 642 b$ & $64 \pm 7 a$ & $949 \pm 209 b$ & $37 \pm 7 b$ & $650 \pm 329 a b$ & $24 \pm 6 a b$ \\
\hline & Median & 1617 & 64 & 959 & 37 & 529 & 22 \\
\hline & Range & $813-2512$ & $47-77$ & $512-1320$ & $21-50$ & $213-1083$ & $11-34$ \\
\hline \multirow[t]{3}{*}{ Rift valley } & Mean \pm SD & $1876 \pm 883 d$ & $67 \pm 8 b$ & $1029 \pm 559 a b$ & $37 \pm 7 c$ & $752 \pm 421 d$ & $27 \pm 8 b$ \\
\hline & Median & 1666 & 68 & 902 & 36 & 640 & 26 \\
\hline & Range & $660-3074$ & $50-80$ & $345-1703$ & $23-47$ & 217-1315 & $13-39$ \\
\hline \multirow[t]{3}{*}{ Lake Victoria } & Mean \pm SD & $1195 \pm$ 449abcd & $66 \pm 7 c$ & $690 \pm 263 a b c$ & $38 \pm 6 d$ & $454 \pm 231 \mathrm{acd}$ & $25 \pm 7 d$ \\
\hline & Median & 1137 & 67 & 630 & 38 & 401 & 24 \\
\hline & Range & 471-1886 & $50-77$ & $275-1081$ & $26-47$ & 135-791 & $12-36$ \\
\hline \multirow[t]{3}{*}{ Coast } & Mean \pm SD & $1617 \pm 574 a$ & $66 \pm 7 d$ & $881 \pm 333 a$ & $36 \pm 7 a$ & $675 \pm 289 a$ & $28 \pm 6 a$ \\
\hline & Median & 1502 & 67 & 854 & 36 & 602 & 28 \\
\hline & Range & $572-2708$ & $51-77$ & $281-1540$ & $22-47$ & 210-1179 & $16-37$ \\
\hline
\end{tabular}

The absolute counts of CD4, CD3 and CD8 are presented as cells/ $\mu \mathrm{L}$ of blood.

Means followed by the same letters within a column are not significantly different from each other according to Tukey's test. 
significant. General reference ranges were also determined as mentioned earlier $(\mathrm{P}<0.05$; Table 2$)$.

\section{T-lymphocyte subset for males and females}

Females had a significantly higher CD3 mean absolute counts $(\mathrm{P}<0.05)$ compared to men. There were significant differences in CD4 counts for males and females. However, there were no significant differences in the mean CD8 absolute counts. T lymphocyte subset reference ranges for males and females separately were also determined at 2.5 and 97.5 percentiles (Table 3).

Table 3 Means, medians and ranges of the lymphocyte subsets for males and females

\begin{tabular}{|c|c|c|c|}
\hline \multirow[t]{2}{*}{ Lymphocyte subset } & \multicolumn{2}{|l|}{ Sex } & \multirow[t]{2}{*}{ p-value } \\
\hline & Female & Male & \\
\hline \multicolumn{4}{|l|}{ CD3 Absolute count } \\
\hline $\mathrm{N}$ & 85 & 222 & \\
\hline Mean & 1787 & 1610 & 0.039 \\
\hline Median & 1701 & 1529 & 0.016 \\
\hline Ranges & $697-2841$ & $581-2641$ & \\
\hline \multicolumn{4}{|l|}{ CD3\% $\times$} \\
\hline Mean & 68 & 66 & 0.026 \\
\hline Median & 69 & 66 & 0.024 \\
\hline Ranges & $54-78$ & $49-78$ & \\
\hline \multicolumn{4}{|l|}{ CD8 Absolute count } \\
\hline Mean & 659 & 644 & 0.743 \\
\hline Median & 568 & 558 & 0.696 \\
\hline Ranges & $187-1180$ & $185-1140$ & \\
\hline \multicolumn{4}{|l|}{$\mathrm{CD} 8 \%^{\times}$} \\
\hline Mean & 25 & 26 & 0.133 \\
\hline Median & 25 & 25 & 0.256 \\
\hline Ranges & $14-34$ & $13-37$ & \\
\hline \multicolumn{4}{|l|}{ CD4 Absolute count ${ }^{*}$} \\
\hline Mean & 1010 & 889 & 0.011 \\
\hline Median & 991 & 855 & 0.001 \\
\hline Ranges & $422-1572$ & $320-1459$ & \\
\hline \multicolumn{4}{|l|}{ CD4\% ${ }^{\times}$} \\
\hline Mean & 40 & 37 & 0.001 \\
\hline Median & 39 & 36 & 0.001 \\
\hline Ranges & $23-53$ & $24-46$ & \\
\hline \multicolumn{4}{|l|}{ CD4/CD8 ratio } \\
\hline Mean & 1.69 & 1.51 & $<0.001$ \\
\hline Median & 1.62 & 1.44 & 0.030 \\
\hline Ranges & $0.55-2.95$ & $0.49-2.64$ & \\
\hline
\end{tabular}

${ }^{*}$ Expressed as cells/ $\mu \mathrm{L}$ of blood.

${ }^{\times}$Expressed as a percentage of total lymphocytes.
T-lymphocyte subset for the different age groups

The means and medians of the lymphocyte subsets were also determined for the different age groups. There were no significant differences in the mean absolute counts in the age groups that were considered in this study (Table 4).

Comparison of the ranges of the current study with those established by other studies

The reference ranges established in this study showed variations with the ones used in MultiSET (BD FACScaliber) as well as other studies in different populations. The studies compared below included normal (HIV negative)

Table 4 The lymphocyte subset levels in the different age groups

\begin{tabular}{|c|c|c|c|c|}
\hline \multirow[t]{2}{*}{ Subset } & \multicolumn{4}{|c|}{ Age group } \\
\hline & $16-19$ & $20-30$ & $31-55$ & $P$ valu \\
\hline \multicolumn{5}{|c|}{ CD3 Absolute count* } \\
\hline $\mathrm{N}$ & 55 & 196 & 62 & \\
\hline Mean & 1603 & 1641 & 1742 & 0.745 \\
\hline Median & 1519 & 1611 & 1622 & 0.595 \\
\hline \multicolumn{5}{|l|}{ CD3\% ${ }^{\times}$} \\
\hline $\mathrm{N}$ & 55 & 196 & 62 & \\
\hline Mean & 65 & 67 & 67 & 0.180 \\
\hline Median & 65 & 67 & 67 & 0.261 \\
\hline
\end{tabular}

CD8 Absolute count ${ }^{*}$

$\begin{array}{lllll}\text { N } & 52 & 181 & 61 & \\ \text { Mean } & 611 & 641 & 693 & 0.870 \\ \text { Median } & 526 & 564 & 636 & 0.498 \\ \text { CD8\% }{ }^{\times} & & & & \\ \text {N } & 52 & 181 & 61 & \\ \text { Mean } & 24 & 26 & 27 & 0.138 \\ \text { Median } & 23 & 25 & 26 . & 0.090\end{array}$

CD4 Absolute count ${ }^{*}$

$\begin{array}{lllll}\text { N } & 55 & 196 & 62 & \\ \text { Mean } & 912 & 898 & 997 & 0.139 \\ \text { Median } & 915 & 882 & 988 & 0.254 \\ \text { CD4\% }^{\times} & & & & \\ \text {N } & 55 & 196 & 62 & \\ \text { Mean } & 38 & 37 & 38 & 0.222 \\ \text { Median } & 36 & 37 & 37 & 0.184\end{array}$

CD4/CD8 ratio

\begin{tabular}{lllll} 
Mean & 1.70 & 1.54 & 1.54 & $<0.001$ \\
Median & 1.63 & 1.45 & 1.51 & 0.135 \\
\hline
\end{tabular}

${ }^{*}$ Expressed as cells $/ \mu \mathrm{L}$ of blood.

${ }^{\times}$Expressed as a percentage of total lymphocytes. ANOVA was used to test the differences in means of the lymphocytes in the age groups. 
populations in their study populations. Most of the studies were regional, that is, having been conducted in specific countries or in some specific regions within the countries (Table 5).

\section{Discussion}

The reference values of the main circulating lymphocyte subsets have been established by many studies throughout the world and have shown some variability according to geographical locations and methodology. Results in Table 5 show comparative values of CD3, CD4 and CD8 subsets levels from other countries, showing variations based on geographical region and platform methods used.

In this study, the mean CD3 count was found to be generally higher compared to those reported in Sweden (1075) but lower in CD3\% mean [3]. In comparison with other African countries the lymphocyte counts and percentages were found to be fairly comparable in some cases but in others slightly different. In addition, Kenya like many African countries (Tanzania, Ghana, Senegal and Ethiopia) had lower lymphocyte subset levels compared to those reported in Sweden $[3,25,26]$.

Considering the two important lymphocyte subsets CD4 and CD8, there were striking variations with the other reported ranges within and outside Africa. The mean CD8 value for this study was similar to those obtained in other African countries but slightly higher than those reported in Tanzania and Senegal $[8,25]$. The CD4 absolute counts were significantly higher than those reported in Ethiopia and Senegal [17] but lower compared to those reported in Kampala Uganda [21]; Table 5. However, the ranges cannot be conclusively compared since the studies differ in experimental set up. For example the study in Uganda included patients who visited an AIDS information center in Kampala, whereas our study was among blood donors across the country. In comparison to other countries outside Africa, the CD4 absolute counts were higher compared to Asian populations [27]. It can be speculated that, these differences in the lymphocyte counts are due to the many factors already mentioned, including genetic predisposition [1-3]. Many of these factors including the genetic influence have not been comprehensively confirmed.

In this study, females had higher absolute counts for CD3 and CD4 lymphocytes compared to males. This was probably due to biological factors (Table 4). It has been speculated that gender and age-related variations within the immune system parameters may contribute to the pathogenesis of several gender and age-related diseases such as autoimmune disorders in female patients $[17,19,24]$. Further, it has been shown that there are gender differences in the generation of CD8 cells during HIV-1 infection, due to increased immune activation compared to men [28]. However, a comparison of mean CD8 absolute counts between males and females, revealed no significant differences. These findings were consistent with previous studies $[2,3,19,24]$.

The study also compared the differences in absolutes counts across regions. There were significant differences across regions with Lake Victoria region, consistently recording lower lymphocyte counts compared to other regions. The CD8 absolute count of Nairobi were appreciably similar with ones reported by Embree [19] in their controls of a study carried out in Nairobi. These observations show that, there is need to understand the impact of genetic makeup and altitude on the levels of $\mathrm{T}$ lymphocytes. The CD4 median absolute counts for the Rift valley $(810$ cells $/ \mu \mathrm{L})$ were similar to the ones reported in one of the studies in Kericho which is located within the valley ([20] Table 2).

Analysis of the lymphocyte subsets in the different age groups revealed no significant differences. A more comprehensive study design might be required to give a clear picture of the lymphocyte changes with advancing age. It is however well known that the pattern of $\mathrm{T}$ lymphocyte generation with age originates from dynamic changes in thymic as well as extrathymic functions, along with

Table 5 Comparison of the reference ranges developed in this study with reference ranges of other populations

\begin{tabular}{llllllll}
\hline Subset & Kenya & MultiSET & Tanzania & Ghana & Italy & Germany & Switzerland \\
\hline CD3 $^{*}$ & $613.9048-2685.439$ & $690-2540$ & NA & NA & $600-2460$ & $780-2240$ & $540-1790$ \\
CD3\% $^{*}$ & $50.3433-78.0606$ & $55-84$ & NA & NA & NA & NA & NA \\
CD4 $^{*}$ & $343.5796-1493.167$ & $410-1590$ & $312.2-1367.6$ & $265-1932$ & $490-1670$ & $490-1640$ & $310-1140$ \\
CD4\% $^{*}$ & $23.7048-48.2465$ & $31-60$ & NA & NA & NA & NA & NA \\
CD8 $^{*}$ & $187.1348-1139.389$ & $190-1140$ & $168.2-996.8$ & $162-1590$ & $220-1110$ & $170-880$ & $140-820$ \\
CD8\% $^{*}$ & $13.3894-36.3925$ & $13-41$ & NA & NA & NA & NA & NA \\
CD4/CD8 ratio & $0.5002-2.7434$ & NA & $1.1-2.5$ & $0.58-4.59$ & NA & $0.9-5.0$ & $1.0-5.0$ \\
\hline
\end{tabular}

${ }^{\mathrm{NA}}$ Not available.

${ }^{*}$ Expressed as cells/ $\mu \mathrm{L}$ of blood.

${ }^{\times}$Expressed as a percentage of total lymphocytes.

Kenya-Current study, MultiSET-BD Biosciences, Tanzania [19], Ghana [2], Italy [24], Germany [25], Switzerland [3]. 
sequential developmental steps from stem cell to ultimately mature cells [29].

\section{Conclusion}

Our study has established ranges and reveals that lymphocyte subsets among the Kenyan population are different from those of other populations in the other populations such as Germany, Italy and Switzerland. However, the ranges are fairly comparable to those reported in some African countries. The ranges are also slightly different from those that are being used currently. This study has established reference ranges for the lymphocyte subsets among healthy Kenyan individuals of the ages between 16-60 years using FACSCalibur flow cytometer (Becton Dickinson Immunocytometry Systems, San Jose, California). The study has further shown the possibility of having varied lymphocyte levels among Kenyan subpopulations, due to many unconfirmed factors. Therefore, the current ranges should be more comprehensively determined and further revised, in order to have accurate comparisons during flow cytometry.

\section{Additional file}

Additional file 1: Questionnaire for sample collection.

\section{Abbreviations}

HIV: Human immunodefieciency virus; CTL: Cytotoxic T lymphocytes; SSC: Side scatter; ANOVA: Analysis of variance.

\section{Competing interests}

The authors declare that they have no competing interests.

\section{Authors' contributions}

EB designed the study, collected samples, analysed them and drafted the manuscript. MMG helped in data analysis and interpretation and reviewed the manuscript. SAK conceptualized the idea, helped in designing experiment, analysis of the samples, interpretation of data and review of the manuscript. AKN helped in drafting and critically revising the manuscript. RL helped in critically reviewing the manuscript. VO helped in critical review of the paper. All authors read and approved the final manuscript.

\section{Acknowledgements}

The authors wish to thank individuals who participated in the study, the staff of all the Regional Blood Transfusion centers for their participation and the Department of Zoological Sciences, Kenyatta University for financial support.

\section{Author details}

'Department of Zoological Science, Kenyatta University, P.O. Box 43844-0100, Nairobi, Kenya. ${ }^{2}$ Department of Plant and Microbial Sciences, Kenyatta University, P. O. Box 43844-0100, Nairobi, Kenya. ${ }^{3}$ Kenya Medical Research Institute, Centre for Viral Research, P.O Box 54840-00200, Nairobi, Kenya.

Received: 15 May 2013 Accepted: 5 November 2013

Published: 7 November 2013

\section{References}

1. Ahmadi K, Hall M, Norman P, Vaughan R, Snieder H, Spector T, Lanchbury J: Genetic determinism in the relationship between human CD4 and CD8 T lymphocyte populations. Genes Immunol 2001, 2:38-387.

2. Ampofo W, Torpey K, Mukadi Y, Koram K, Nolan K, Amenyah R, Kaitoo E, Antwi P, Ofori-adjei D, Lamptey P: Normal CD4T lymphocyte levels in HIV seronegative individuals in the Manya/Yilo Krobo communities in the Eastern Region of Ghana. Viral Immunol 2006, 19:260-266.

3. Bisset L, Lung T, Kaelin M, Ludwig E, Dubs R: Reference values for peripheral blood lymphocyte phenotypes applicable to the healthy adult population in Switzerland. Eur J Haematol 2004, 72:203-212.

4. Illoh O: Current applications of flow cytometry in the diagnosis of primary immunodeficiency diseases. Arch Pathol Lab Med 2004, 128:23-31.

5. Davis W, Hamilton M: Uses of flow cytometry to characterize immunodeficiency syndromes in Camelids. Small Ruminant Res 2006 61(2):187-193.

6. Ullrich K, Koenigsmann M, Mohren M, Franke A: Lymphocyte subsets' reference ranges in an age-and gender-balanced population of 100 healthy adults-a monocentric German study. Clin Immunol 2005, 116:192-197.

7. Howard R, Fasano C, Frey L, Miller C: Reference intervals of CD3, CD4, CD8, CD4/CD8, and absolute CD4 values in Asian and non-Asian populations. Cytometry 1996, 26:231-232.

8. Mandy F, Nicholson J, McDougal J: Revised guidelines for performing single-platform absolute CD4+ T-Cell determinations with CD45 gating for persons infected with human immunodeficiency virus. MMWR 2003, 52:1-13.

9. Klose N, Coulibaly B, Tebit D, Nauwelaers F, Spengler H, Kynast-Wolf G, Kouyaté $\mathrm{B}$, Kräusslich $\mathrm{H}$, Böhler T: Immunohematological reference values for healthy adults in Burkina Faso. Clin Vaccine Immunol 2007, 14:782-784.

10. Lahita R: Sex hormones and systemic lupus erythematosus. Rheum Dis Clin North Am 2000, 26:951-968.

11. Vajpayee M, Kaushik S, Sreenivas V, Wig N, Seth P: CDC staging based on absolute CD4 count and CD4 percentage in an HIV-1-infected Indian population: treatment implications. Clin Exp Immunol 2005, 141:485-490.

12. Kalayjian R, Landay A, Pollard R, Taub D, Gross B, Francis I, Sevin A, Pu M, Spritzler J, Chernoff M, Namkung A, Fox L, Martinez A, Waterman K, Fiscus S, Sha B, Johnson D, Slater $S$, Rousseau F, Lederman M: Age related immune dysfunction in health and in human immunodefieciency virus (HIV) disease: association of age and HIV infection with naive CD8 cell depletion, reduced expression of CD28 on CD8 cells and reduced thymic volumes. J Infect Dis 2003, 187:1924-1933.

13. Olsen $N$, Kovacs W: Effects of androgens on $T$ and $B$ lymphocyte development. Immunol Res 2001, 23:281-288.

14. Clerici M, Butto S, Lukwiya M: Immune activation in Africa is environmentallydriven and is associated with upregulation of CCR5: Italian-Ugandan AIDS project. AIDS 2000, 14:2083-2092.

15. Menard D, Joelle M, Bem M, Kassa E, Gresenguet G, Talarmin A: Immunohematological reference ranges for adults from the central African republic. Clin Diagn Lab Immunol 2003, 10:443-445.

16. Schaberge T, Theilacker C, Nitschke O, Lode H: Lymphocyte subsets in peripheral blood and smoking habits. Lung 1997, 175:387-394.

17. Mair C, Hawes S, Agne H, Sow P, N'dove I, Manhart L, Fu P, Gottlieb G, Kiviat N: Factors associated with CD4 lymphocyte counts in HIV-negative Senegalese individuals. Clin Exp Immunol 2007, 151:432-440.

18. Feldman G, Minkoff $H$, Schneider F: Association of cigarette smoking with HIV prognosis among women in the HAART era: a report from the women's interagency HIV study. Am J Pub Health 2006, 96:1060-1065.

19. Ngowi B, Mfinanga S, Bruun J, Morkve O: Immunohaematological reference values in human immunodeficiency virus-negative adolescent and adults in rural northern Tanzania. BMC Infect Dis 2009, 9:1-7.

20. Kibaya R, Bautista C, Sawe F, Schaffer D, Sateren W, Scott P, Michael N, Robb M, Birx D, Souza M: Reference ranges for the clinical laboratory derived from a rural population in Kericho Kenya. PlOS ONE 2008, 3(10):e3327. Doi:10.1371/journal.pone.0003327.

21. Tugume S, Piwowar E, Lutalo T, Mugyenyi P, Grant R, Mangeni F, Pattishall K, Katongole-Mbidde E: Hematological reference ranges among healthy Ugandans. Clin Diagn Lab Immunol 1995, 2:233-235.

22. Embree J, Bwayo J, Nagelkerke N, Njenga S, Nyange P, Ndinya-Achola J, Pamba H, Plummer F: Lymphocyte subsets in human immunodeficiency virus type 1-infected and uninfected children in Nairobi. Pediatr Infect Dis J 2001, 20:397-403.

23. NCCLS: How to define and determine reference intervals in the clinical laboratory; approved quideline, Volume 20. 2nd edition. Wayne, PA: National Committee for Clinical Laboratory Standards; 2000:13. C28-A2.

24. Santagostino A, Garbaccio G, Pistorio A, Bolis V, Camisasca G, Pagliaro P, Girotto M: An Italian national multicenter study for the definition of 
reference ranges for normal values of peripheral blood lymphocyte subsets in healthy adults. Haematologica 1999, 84:499-504.

25. Koetz K, Bryl E, Spickschen K, O'Fallon W, Goronzy J, Weyand C: T-cell homeostasis in patients with rheumatoid arthritis. Proc Natl Acad Sci USA 2000, 97:9203-9208.

26. Nicholson J, Stein D, Mui T, Mack R, Hubbard M, Denny T: Evaluation of a method for counting absolute numbers of cells with a flow cytometer. Clin Diagn Lab Immunol 1997, 4:309-313.

27. Chng W, Guat B, Tan S, Kuperan P: Establishment of adult peripheral blood lymphocyte subset reference range for an Asian population by single-platform flow cytometry: influence of age, sex, and race and comparison with other published studies. Clin Diagn Lab Immunol 2004, 11:168-173.

28. Meier A, Chang J, Chan E, Pollard R, Sidhu H, Kulkarni S, Wen T, Lindsay R, Orellana L, Mildvan D, Bazner S, Streeck H, Alter G, Lifson J, Carrington M, Bosch R, Robbins G, Altfeld M: Sex differences in the Toll-like receptormediated response of plasmocytoid dendritic cells to HIV-1. Nat Med 2009, 15:955-959.

29. Globerson A: Thymocytopoiesis in aging: the bone marrow-thymus axis. Arch Gerontol Geriatr 1997, 24:141-155.

doi:10.1186/1742-6405-10-24

Cite this article as: Bosire et al:: Population specific reference ranges of CD3, CD4 and CD8 lymphocyte subsets among healthy Kenyans. AIDS

Research and Therapy 2013 10:24.

\section{Submit your next manuscript to BioMed Central and take full advantage of:}

- Convenient online submission

- Thorough peer review

- No space constraints or color figure charges

- Immediate publication on acceptance

- Inclusion in PubMed, CAS, Scopus and Google Scholar

- Research which is freely available for redistribution 